\title{
Effect of Climate Change on Water Resources
}

\author{
Solomon Melaku Melese \\ Department of Forestry, College of Agriculture, Wollo University, Dessie, Ethiopia
}

Email address:

Solomon.melaku@wu.edu.et

\section{To cite this article:}

Solomon Melaku Melese. Effect of Climate Change on Water Resources. Journal of Water Resources and Ocean Science. Vol. 5, No. 1, 2016, pp. 14-21. doi: 10.11648/j.wros.20160501.12

\begin{abstract}
Climate change is one of the global issue that would affect the sustainable development of many regions. The objective of this review is the effect of climate change on water resources. Climate change affects certain components of the hydrological cycle, especially precipitation and runoff. A change in climate can alter the spatial and temporal availability of water resources. The effects of minor levels of climate change are already being felt, with impacts across many economic sectors. These changes will result in increased floods and drought, which will have significant impacts on the availability of freshwater. These impacts on freshwater will be further compounded by rising sea levels, and melting glaciers. In general a warmer climate will accelerate the hydrologic cycle, altering rainfall, magnitude and timing of run-off.
\end{abstract}

Keywords: Climate, Water, Effect

\section{Introduction}

Scientific evidence indicates that due to increased concentration of greenhouse gases in the atmosphere, the climate of the Earth is changing; temperature is increasing and the amount and distribution of rainfall is being altered (Houghton et al. 1996). The IPCC Scientific Assessment suggests that global average temperature may increase between 1.5 and $4.5^{\circ} \mathrm{C}$, with a 'best estimate' of $2.0^{\circ} \mathrm{C}$, in the next century with a doubling of the $\mathrm{CO}_{2}$ concentration in the atmosphere (Houghton et al. 1996). The United Nations Framework Convention on Climate Change (UNFCCC) defines climate change as, "a change of climate which is attributed directly or indirectly to human activity that alters the composition of the global atmosphere and which is in addition to natural climate variability observed over comparable time periods". Climate change affects certain components of the hydrological cycle, especially precipitation and runoff. A change in climate can alter the spatial and temporal availability of water resources. It reduces either the overall quantity of water or the timing of when water is available for use will have important effects on agriculture, industrial and urban development.

The climatic impact on the water regime may also make worse other environmental and social effects of water management. For instance, reduced river runoff can concentrate the effects of pollutants or exacerbate the spread of water-borne disease. Climate fluctuations can also affect the use of agricultural land associated with irrigation systems. Climate change will greatly complicate the design, operation, and management of water-use systems (Gleick and Shiklomanov, 1989). Scientists around the world now agree that the climatic changes occurring internationally are the result of human activity. Although responsibility for the causes of climate change rests primarily with the developed and industrialized nations, the expenses of climate change will be bear most directly by the poor. This is for a number of reasons including: - many of the region's most likely to be adversely affected fall in the developing world; the poor are disproportionately dependent on occupations, such as farming, that are adversely affected by climate change and because the poor have very limited resources, they do not have the ability to adapt to climate change in the way that wealthier households can. In particular, changes to water quality, quantity and availability will be an impact of ongoing climate change in many areas.

As (Kinfe, 1999)reported on Awash River the general warming simulated by General circulation models (GCMs) under $\mathrm{CO}_{2}$ doubling would result in a substantial decrease in annual runoff over the Awash River Basin. In addition to this, the total average annual inflow volume into Lake Zuway might decline significantly. This is likely to drop the lake level up to two third of a meter and shrink the water surface area up to $25 \mathrm{~km} 2$, which is about $6 \%$ of the base period water surface area. This combined with the unbalanced supply-demand equation in the watershed is expected to have 
significant impact on the lake water balance. Therefore, in Lake Zuway Watershed, runoff is likely to decrease in the future and be insufficient to meet future demands for water of the ever increasing population (Lijalem, et al. 2007). Some Current scientific research shows that climate change will have major effects on precipitation, evapotranspiration, and runoff and ultimately on the nations water supply. Climateinduced changes in the water cycle likely will affect the magnitude, frequency, and costs of extreme weather events as well as the availability of water to meet growing demand (Frederick and Gleick, 1999).The objective of this graduate seminar is to review the effect of climate change on water resources.

\section{The Impacts of Climate Change on Critical Areas}

The effects of minor levels of climate change are already being felt, with impacts across many economic sectors. While there will clearly be some gains from climate change (for example, agriculture in some northern regions should increase in productivity due to a rise in temperatures). But, most of the impacts will be negative, and gains and losses will not be evenly distributed. Of the major critical areas:-

Water: Rising global temperatures will lead to an intensification of the hydrological cycle, resulting in dryer dry seasons and wetter rainy seasons, and subsequently sensitive risks of more extreme and frequent floods and drought occurrence. Changing climate will also have significant impacts on the availability of water, as well as the quality and quantity of water that is available and accessible. Melting glaciers will increase flood risk during the rainy season, and strongly reduce dry-season water supplies to onesixth of the World's population.

Agriculture: Declining crop yields are likely to leave hundreds of millions without the ability to produce or purchase sufficient food supplies, especially in Africa. At mid to high latitudes, crop yields may increase for low levels of change in temperature, but will decline at higher levels of temperature change.

Ecosystems: Ecosystems are fundamentally dependent on water resources: healthy ecosystems depend on receiving appropriate amounts of water of a certain quality at certain times. Humans, in turn, are dependent on ecosystem processes. For example, primary productivity and inputs from watersheds support food webs, yielding fish for commercial and recreational purposes, while decomposition and biological uptakes remove organic materials and nutrients, purifying water. Ecosystem processes are affected by temperature and flow regimes will be affected by changes in climatic conditions. Changing temperatures will cause ecosystems to shift. Forests, land types and plant species will dieback in some areas as temperatures rise, but increase in other areas. However, in many cases, the speed of change in temperature may be too fast for ecosystems to adjust, resulting in the loss of forests and species. Work across the
United States suggests a wide range of serious concerns for ecosystems, with possible extinction of endemic fish species already close to their thermal limits, declining area of wetlands with reductions in waterfowl populations, concerns about stream health, and major habitat loss (Eaton et al., 1996; Covich et al., 1997; Hauer et al., 1997; Meyer, 1997; Schindler, 1997). Researchers also express concern not only about the actual impacts of climate change, but also about the limited ability of natural ecosystems to adapt to or cope with those changes over the short time frame in which the impacts are likely to occur. This limited ability to adapt may lead to irreversible impacts such as species extinction.

Health: Higher temperatures expand the range of some dangerous vector-borne diseases, such as malaria, which already kills one million people annually, most of whom are children in the developing world. Further, heat waves associated with climate change, and increases in water borne diseases, will result in increased health problems

\section{Climate Change and the Hydrological Cycle}

Land use change is directly related with hydrological cycle (Sreenivasulu and Bhaskar 2010) and, any change in land use and shifting cultivation is the major cause for large-scale changes in associated ecosystem (Chakraborty 2009). Since, much of the solar energy received by the Earth is used to drive the hydrological cycle, higher levels of solar energy trapped in the atmosphere will lead to an intensification of this cycle which resulting in changes in precipitation patters. These changes will result in increased floods and drought, which will have significant impacts on the availability of freshwater. These impacts on freshwater will be further compounded by rising sea levels, and melting glaciers. In general a warmer climate will accelerate the hydrologic cycle, altering rainfall, magnitude and timing of run-off. Warm air holds more moisture and increase evaporation of surface moisture. With more moisture in the atmosphere, rainfall and snowfall events tend to be more intense, increasing the potential for floods. However, if there is little or no moisture in the soil to evaporate, the incident solar radiation goes into raising the temperature, which could contribute to longer and more severe droughts (Mall R. K. et al, 2006). Therefore, fig 1 showed that change in climate will affect the soil moisture, groundwater recharge and frequency of flood or drought occurrence and finally groundwater level in different areas. Changes in the water cycle, which are consistent with the warming observed over the past several decades, include:

- Changes in precipitation patterns and intensity

- Changes in the occurrence of drought

- Widespread melting of snow and ice

- Increasing atmospheric water vapor

- Increasing evaporation

- Increasing water temperatures

- Changes in soil moisture and runoff and so on. 


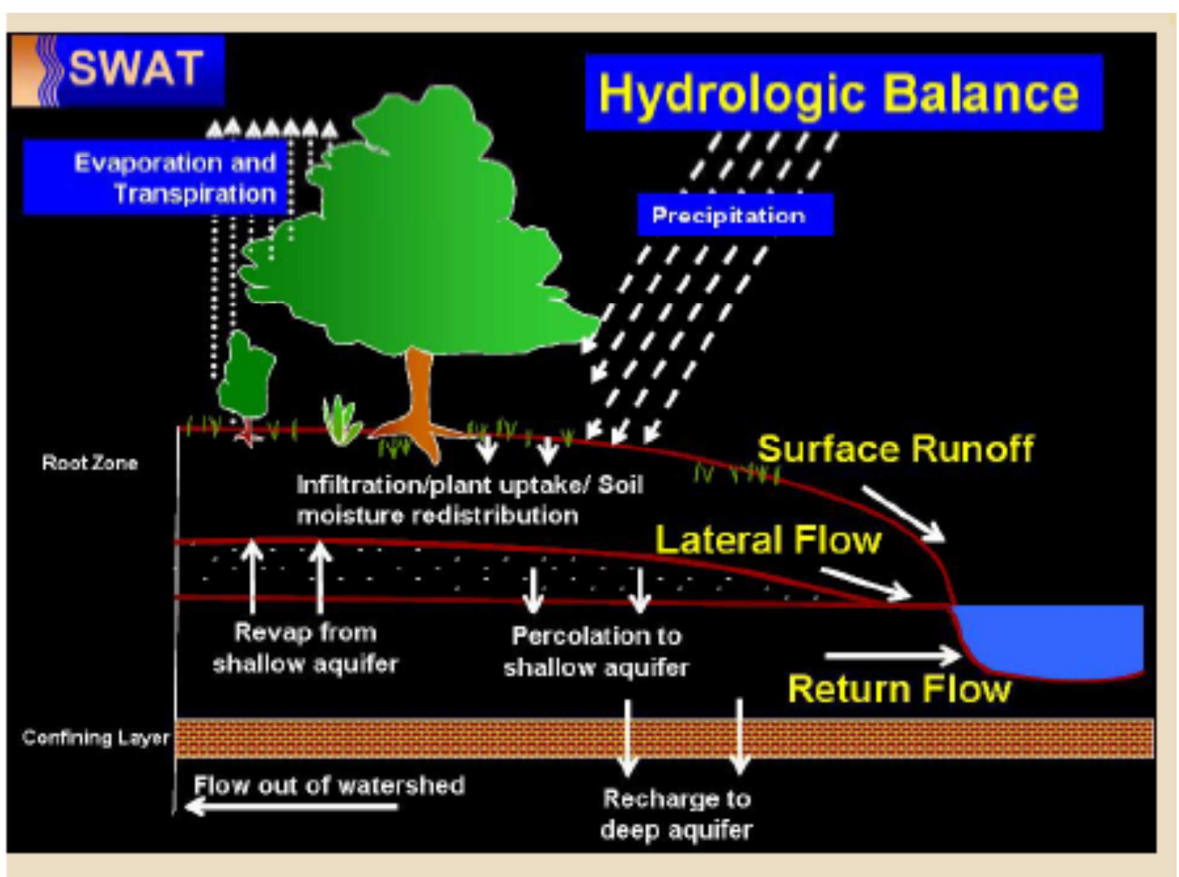

Fig. 1. Soil and water assessment tool.

\subsection{Floods and Drought}

Floods and droughts are likely to become more common and more intense as regional and seasonal precipitation patterns change, and rainfall becomes more concentrated into heavy events. While it sounds when, a warmer world produces both wetter and drier conditions. Even though total global precipitation increases, the regional and seasonal distribution of precipitation changes and more precipitation comes in heavier rains (which can cause flooding) rather than light events (Frederick and Major, 1997). In the past century, averaged over the United States, total precipitation has increased by about 7 percent, while the heaviest 1 percent of rain events increased by nearly 20 percent. Flooding often occurs when heavy precipitation persists for weeks to months in large river basins. Observations also show that over the past several decades, extended dry periods have become more frequent in parts of the United States, especially the Southwest and the eastern United States. Longer periods between rainfalls, combined with higher air temperatures, dry out soils and vegetation, causing drought. For the future, precipitation intensity is projected to increase everywhere, with the largest increases occurring in areas in which average precipitation increases the most (Matalas and Fiering, 1977). The number of dry days between precipitation events is also projected to increase, especially in the more arid areas. Mid-continental areas and the Southwest are particularly threatened by future drought. So the combination of more intense and frequent storms with land use changes is already proving to be deadly for the world's vulnerable populations. In drier regions, even a slight rise in temperatures will lead to greater loss of moisture, exacerbating drought and desertification (Frederick and Major, 1997). Drought will lead to decreased water availability and water quality for populations in many waterscarce regions, particularly in southern Africa, North Africa, Central America and central Asia. When less precipitation and higher temperatures occur simultaneously, the availability of water resources is reduced even further while evaporation is increased, leading to a vicious cycle. In SubSaharan Africa, for example, long periods of drought are becoming more common and are predicted to become more widespread. While some farmers have been able to survive by selecting seed varieties based on changing conditions, poorer farmers have not been as able to adapt.

\subsection{Rising Sea Levels}

Sea levels rising in response to thermal expansion of the oceans and increased melting of glaciers and land ice will also affect water availability. The global sea level increased about $18 \mathrm{~cm}$ during the past century. The most recent IPCC results suggest average sea level might rise another 15 to 95 $\mathrm{cm}$ by the year 2100 . Changes in sea level will increase coastal erosion, and flooding of wetlands and lowlands. It will also have a significant impact on the availability of freshwater: Higher sea levels and increased storm surges could adversely affect freshwater supplies in coastal areas. Salt water in river mouths and deltas would advance inland and coastal aquifers would face an increased threat of saltwater intrusion, jeopardizing the quality of water for many domestic, industrial, and agricultural users. For example, sea level rise would aggravate water-supply problems in several coastal areas in the United States, including Long Island, Cape Cod, New Jersey shore communities, and the Florida cities of Miami, Tampa, and 
Jacksonville (Frederick and Major, 1997). As the level of the sea rises, additional scarce freshwater supplies are required to prevent saltwater interruption into the delta or farm land. In general, sea level rise end with salinity problems and makes the productive land unproductive or useless.

\subsection{Melting Glaciers}

Scientists are especially concerned about the Arctic, where the effects of climate change are being felt more quickly and severely than anywhere else on the planet. Arctic temperatures increased by about 5 degrees during the $20^{\text {th }}$ Century - 10 times faster than the global average. Snow cover has declined by some 10 percent in the mid-high latitudes of the Northern Hemisphere since the late 1960s and, in the Russian Arctic, buildings are collapsing because of melting permafrost under the foundations. The dramatic changes occurring in the Arctic are being felt around the world: melting glaciers contribute to rising sea levels, and also increased flash floods as river basins fill more quickly and with a greater volume of water, with the resulting impacts on freshwater availability.

\section{Effect of Climate Change on Ground Water}

Groundwater will be less directly and more slowly impacted by climate change, as compared to surface water (e.g. rivers). So, ground water is less expected to be affected by climate change. This is because rivers get replenished on a shorter time scale, and drought and floods are quickly reflected in river water levels since, river water temperature ere in close equilibrium with air temperature and as air temperature rise so will river temperatures (Hammond and pryce,2007; Hassan et al.,1998). Groundwater, on the other hand, will be affected much slower. Only after prolonged droughts groundwater levels will show declining trends. Global warming as part of climate change will affect ground water indirectly. Groundwater is the intricate, but often overlooked, link between surface waters and many freshwater and terrestrial ecosystems. As many groundwater systems both discharge into and are recharged from surface water, impacts on surface water flow regimes are expected to affect groundwater. Thus neglecting the consideration of groundwater in the process of IWRM can result in the mismanagement of surface water with severe effects on the population and the environment. Increased variability in rainfall may decrease groundwater recharge in humid areas because more frequent heavy rain will affects the infiltration capacity of the soil, thereby increasing surface runoff. In semi-arid and arid areas, however, increased rainfall variability may increase groundwater recharge, because only high-intensity rainfalls are able to infiltrate fast enough before evaporating, and alluvial aquifers are recharged mainly by inundations during floods.

\section{Impact of Climate Change on Water Resources for Human Development}

Access to water plays a key role in development. It sustains human life, both through direct consumption and use in agriculture and industrial activities. Availability of water for drinking purposes is also essential and it cannot be separated from wider water resource management issues. The competition between households, agriculture and industry on water can cause conflict over water availability and use. Today, more than one billion people still lack access to safe water, while over two billion lack safe sanitation.

\subsection{Changes in the Quantity, Quality and Accessibility of Water Supplies}

\subsubsection{Quantity of Water}

Many of the world's countries already struggle under existing water stress from pressures such as irrigation demands, industrial pollution and water borne sewerage. These pressures will be significantly exacerbated by climate change, which for many regions will result in reduced rainfall and increasing temperatures, further reducing the availability of water for drinking, household use, agriculture and industry. The Stockholm Environment Institute estimates that, based on only a moderate climate change, by 2025 the proportion of the world's population living in countries of significant water stress will increase from approximately 34 percent (in 1995) to 63 percent For example, in Africa's large catchment basins of Niger, Lake Chad and Senegal, the total available water has already decreased by $40-60$ percent, and desertification has been aggravated by lower than average annual rainfall, runoff and soil moisture, especially in Northern, Southern and Western Africa. The consequences for water supply include smaller flows in springs and rivers, and decreasing groundwater levels. In case of Ethiopia also some rivers and lake size are shrinking for example, lake Zuway drops to level up to two third of a meter and shrink the water surface area up to 25 $\mathrm{km} 2$, which is about $6 \%$ of the base period water surface area. This declining in quantity of water affects local user including farmer and investor. As these competing demands intensify under climate change, effective governance for balancing water demands will become essential, particularly in the face of strong pressures to prioritize industrial uses over other uses such as drinking supplies.

\subsubsection{Quality of Water}

Climate change is expected to affect water quality in both inland and coastal areas. Specifically, precipitation is expected to occur more frequently via high-intensity rainfall events, causing increased runoff and erosion. More sediments and chemical runoff will therefore be transported into streams and groundwater systems, impairing water quality. Water quality may be further impaired if decreases in water supply cause nutrients and contaminants to become more concentrated. Rising air and water temperatures will also impact water quality by increasing primary production, 
organic matter decomposition, and nutrient cycling rates in lakes and streams, resulting in lower dissolved oxygen levels. Lakes and wetlands associated with return flows from irrigated agriculture are of particular concern. This suite of water quality effects will increase the number of water bodies in violation of today's water quality standards, worsen the quality of water bodies that are currently in violation, and ultimately increase the cost of meeting current water quality goals for both consumptive and environmental purposes (Adams R. M. et al, 2008). The quality of existing water supplies will become a further concern in some regions of the globe. Water acquires most of its geochemical and biochemical substance during its cycle from clouds to rivers, through the biosphere, soils and geological layers. Changes in the amounts or patterns of precipitation will change the route/ residence time of water in the watershed, thereby affecting its quality. For example, in areas with relatively high water tables, or under intensive irrigation, increased evaporation due to higher temperatures will raise the concentration of dissolved salts. Further, increased flooding could raise water tables to the point where agrochemicals/ industrial wastes from soil leach into the groundwater supply. Similarly, higher ocean levels will lead to salt water intrusion in coastal groundwater supplies, threatening the quality and quantity of freshwater access to large populations.

\subsubsection{Accessibility of Water}

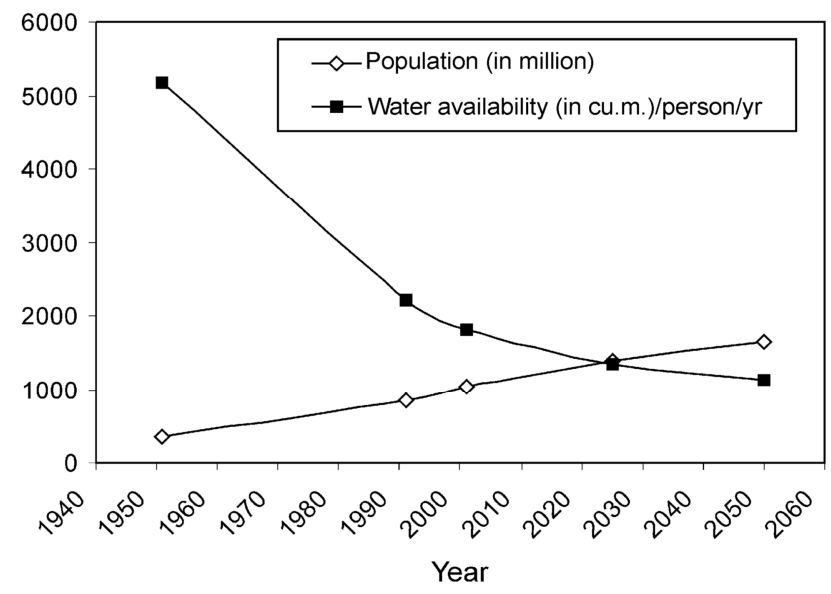

Source: Ministry of Water Resources, Govt of India (2003).

Fig. 2. Average annual freshwater availability and growth of population from 1951 to 2050.

As water quantities and quality decrease as a result of intensification of the hydrological cycle, competition for available resources will intensify. Demand for agricultural and domestic water in particular increases significantly at hotter and drier times of the year. Agriculture has always been the dominant end-use of diverted water; this will only intensify with increasing needs for irrigation brought on by higher temperatures and reduced precipitation, coupled with increasing populations. Meanwhile, demands of industry are expected to become a greater issue in the competition for dwindling resources; in the event of decreasing water tables as a result of climate change, industrial needs will be forced to compete with agricultural and domestic water supply sources, and could lead to conflict. In general, in this century population numbers are increasing from time to time with declining water resources. This figure 2 shows the observed and projected decline in per capita average annual freshwater availability and growth of population from 1951 to 2050 in India.

\subsection{Natural Disasters}

The increase in natural disasters, primarily floods and droughts, will further exacerbate issues over water availability and water quality. The Intergovernmental Panel on Climate Change (IPCC) has projected that flooding and landslides pose the most widespread direct risk to human settlements from climate change. The UNFCCC predicts that "a future of more severe storms and floods along the world's increasingly crowded coastlines is likely, and will be a bad combination even under the minimum scenarios forecast". Beyond the immediate and apparent destruction caused by flooding, it also includes loss of life and livelihoods. Flooding has major impacts on water resources, and so humans through:-

- Overburdening of wastewater and drain systems, leading to contamination of water supplies with subsequent outbreaks of dysentery and cholera.

- Disruption of safe water supplies through damage to infrastructure.

- Flood water in low land area creates breeding grounds for mosquitoes with increased risk of malaria, yellow fever and dengue

- Floods can also increase the incidence of diseases such as skin diseases as a result of constant contact with water; and

- Inadequate nutrition following disruption of income and food distribution systems.

\section{Consequences for Human Populations}

Effect of climate change on water resource is not affects human population only through quantity, quality and accessibility but also through affecting agriculture, health, economic activity, and conflicts over water resources. The potential of Landsat image data is to provide an accurate classification for land cover changes over time (Tsarouchi and Buytaert 2013). Normalized Difference Vegetation Index (NDVI) method is better suitable where analysis is carried out using either past or present images with no ground truth data (Chandrabose et al. 2012).

\subsection{Impacts to Agriculture and Food Security}

Agriculture is the sector that dominantly affected by climate changes, spatially in developing countries since their agriculture is dependent on rain fails. In addition to this, population pressures are also another problem that needs intensified agricultures. Warmer temperatures will lead to 
increased water evaporation, intensifying the need for irrigation precisely as water becomes even less available. (Shiklomonov, 2003) predicts that water withdrawal for agriculture will rise from $2600 \mathrm{~km}^{3}$ in 2000 to $3200 \mathrm{~km}^{3}$ by 2025. Increasing supply for irrigation will simply not be feasible in many regions, particularly where irrigation capacity is not sufficiently developed to accommodate changing precipitation patterns. In sub-Saharan Africa, for example, where up to 90 percent of agriculture is rain fed, the sector accounts for 70 percent of employment and 35 percent of GNP, and changes in rainfall will havea significant social and economic impact. Meanwhile, it is estimated that a temperature increase of 2-3.5 degrees Celsius in India could result in a decline in farm revenues of between 9 and 25 percent. The International Rice Research Institute, for example, estimates that for every degree Celsius of night time temperature increase, there is at least a 10 percent decrease in rice production for the African region. While some areas will benefit from longer growing seasons (such as northern Asia), changes in water regimes will render other areas unsuitable for traditionally-grown products, and others areas will become susceptible to new forms of crop and livestock diseases. In regions already affected by food shortage and famine, this could cause further disruptions in food supply. The United Nations Development Programme (UNDP) warns that the progress in human development achieved over the last decade may be slowed down or even reversed by climate change, as new threats emerge to water and food security, agricultural production and access, and nutrition and public health. The contribution of climate change for sea level rise, droughts, heat waves, floods and rainfall variation could, by 2080 , push another 600 million people into malnutrition and increase the number of people facing water scarcity by 1.8 billion (UNDP, 2008). Agriculture constitutes the backbone of most African economies. It is the largest contributor to GDP; the biggest source of foreign exchange, accounting for about $40 \%$ of the continent's foreign currency earnings; and the main generator of savings and tax revenues. In addition, about two-thirds of manufacturing value-added is based on agricultural raw materials. Agriculture remains crucial for pro-poor economic growth in most African countries, as rural areas support 70$80 \%$ of the total population. More than in any other sector, improvements in agricultural performance have the potential to increase rural incomes and purchasing power for large numbers of people to lift them out of poverty (NEPAD, 2002; Wiggins, 2006). Climate change, however, is considered as posing the greatest threat to agriculture and food security in the 21 st century, particularly in many of the poor, agriculturebased countries of sub-Saharan Africa (SSA) with their low capacity to effectively cope (Shah et al., 2008; Nellemann et al., 2009).

\subsection{Health Impacts}

Clearly, the health implications of changes to water supply are far-reaching. Currently, more than

3 million people die each year from avoidable water- related disease; most of them are in developing countries. The effects of climate change on water will exacerbate the existing implications of water shortages on human health, as follows:

- Water-borne diseases: result from the contamination of water by human/ animal faeces, or by urine infected with pathogenic viruses/ bacteria, both of which are more likely to occur during periods of flood and therefore intensify with the projected increases in natural disasters under climate change. Diseases are transmitted directly when the water is drunk or used in food preparation.

- Water-washed diseases: those resulting from inadequate personal hygiene as a result of scarcity or inaccessibility of water (including many water-borne diseases and typhus).

- Water-based diseases: those caused by parasites that use intermediate hosts living in/ near water (e.g. guinea worm).

- Water-related diseases: borne by insect vectors that has habitats in/near water (such as malaria).

- Water-dispersed diseases: infections for which the agents proliferate in fresh water and enter the human body through the respiratory tract (e.g. legionella). Further indirect health challenges include malnutrition arising from agricultural disruption and food insecurity.

\section{Possible Soulution on Climate Change}

Climate is just one of many factors challenging future water planners and managers. Indeed, changes in population, economic conditions, technology, policies, and the relative value society places on alternative water uses may be more important determinants of future supply and demand conditions than those attributable to climate change (IPCC, 1996b). Vulnerability, or the sensitivity and potential magnitude of damage associated with climate changes, may also be greatest for regions where current stress on water resources is high. There are two ways to manage the risks posed by climate change: mitigation of GHGs to slow or reverse the pace of climate change, and adaptation to climate impacts to minimise their effects.

\subsection{Mitigation}

Mitigation implies the human measures, structural and non-structural, undertaken to limit the adverse impacts of climate change by reducing the levels of GHGs in the atmosphere. This is accomplished through the development of appropriate technology for reducing emissions and/ or capturing them at their source. Examples of mitigation include measures such as energy efficiency, promotion of renewable energy sources, and carbon trading. Mitigation of GHGs is essential to slow the impact of climate change and it is the most cost-effective and least risky strategy for reducing the future effects of climate change. This is mostly the issue of developed world being they release mere GHGs from their industries. 


\subsection{Adaptation}

Climate change is already occurred; even if mitigation efforts were immediately able to reduce global carbon emissions to zero, there will be certain and ongoing impacts from climate change that need to be addressed. Adaptation describes a set of responses to the actual and potential impacts of climate change to moderate the harm or take advantage of the opportunities that climate change may bring. In countries where the majority of poor people depend on agricultural income, proposed climate change adaptation strategies centre on increasing agricultural productivity and make their agriculture more diversified; including livestock, fishery and forestry that less vulnerable to climate stress and shocks. Beside to this Water management for agricultural production is a critical component that needs to adapt in the face of both climate and socio-economic pressures in the coming decades (Bates et al., 2008). With regard to agricultural production and water, climate change adaptation may include:

- Adoption of varieties and species of crops with increased resistance to heat stress, shock and drought. For example, a private-public partnership under the leadership of the African Agricultural Technology Foundation called Water Efficient Maize for Africa (WEMA) intends to develop drought-tolerant African maize.

- Modification of irrigation techniques, including amount, timing or technology (e.g. drip irrigation systems);

- Adoption of water-efficient technologies to 'harvest' water, conserve soil moisture (e.g. crop residue retention, zero-tillage), and reduce siltation and saltwater intrusion;

- Improved water management to prevent water logging, erosion and nutrient leaching;

- Modification of crop calendars, i.e., timing or location of cropping activities;

- Integration of the crop, livestock, forestry and fishery sectors at farm and catchment levels;

- Implementation of seasonal climate forecasting.

- Enhancing stakeholder participation in water development and climate change adaptation

\section{Conclution}

About two-thirds of the population of the world will become more vulnerable to availability and use of water due to climate changes. It is one of the global issue that would affect the sustainable development of many regions. Regional acidification from industrial activity, water pollution (indirectly through air pollution and directly through discharge of pollutants from industrial activity and sewage disposal), desertification, and soil erosion may also be major threats to water resources.

One of the most significant impacts of climate change is likely to be on the hydrological system, and hence on river flows and regional water resources. This will be particularly true in arid and semiarid areas of Africa where water resources are very sensitive to climate variability, particularly rainfall. Climate change is predicted to have serious implications for the hydrology of the sub-basin, affecting the magnitude and seasonality of surface flows, and increasing the frequency of extreme events such as drought and floods. 34Even if Ethiopia is also known as a tower of east Africa, today many rivers and lakes become shrinking in size due to the decrease in river flow and some small streams dry up completely, and finally the magnitude of flow of the medium to large rivers will decrease significantly.

\section{References}

[1] Adams, R.M and D. E. Peck. 2008. "Effects of Climate Change on Drought Frequency: Impacts and Mitigation Opportunities"; Chapter 7 in Mountains, Valleys, and Flood Plains: Managing Water Resources in a Time of Climate Change. A. Dinar and A. Garrido, eds. Routledge Publishing.

[2] Bates, B.C., Kundzewicz, Z.W., Wu, S. and Palutikof, J.P. (eds) 2008. 'Climate Change and Water'. Technical Paper of the Intergovernmental Panel on Climate Change. Geneva: IPCC Secretariat.

[3] Chandrabose AS, Viswanath GK, Giridhar MVSS, Sridhar P (2012) Assessment of land use land cover changes in middle Godavari (G-5) sub-basin of river Godavari using RS and GIS.

[4] Covich, A.P., S.C. Fritz, P.J. Lamb, R.D. Marzolf, W.J. Matthews, K.A. Poiani, E.E. Prepas, Ecosystems of the Great Plains of North America." Hydrological Processes 11: 9931021.

[5] Eaton, J.G., and R.M. Scheller. 1996. "Effects of Climate Warming on Fish Thermal Habitats in Streams of the United States." Limnology and Oceanography 41(5): 1109-1115.

[6] Fredeick. K. D. and Gleick. P. H. 1999. Water and global climate change: Potential Impacts on U.S. Water Resources; Prepared for the Pew Center on Global Climate Change.

[7] Frederick, K.D., and D.C. Major. 1997. "Climate Change and Water Resources." Climatic Change 37: 7 - 23.

[8] Gleick P, Shiklomanov IA. 1989. The impact of climate change for water resources. Second meeting of IPCC WG-2, WMO/UNEP, Geneva.

[9] Hammond, D. and Pryce, A.R., 2007. Climate change impacts and water temperature. Environment Agency Science Report SC060017SR. 111PP.

[10] Hassan, H., Aramaki, T., Hanaki, K., Matsuo, T. and Wilby, R.L., 1998. Lake stratification and temperature profiles simulated using downscale GCM output. J. Water Sci. Technol., 38, 217-226.

[11] Hauer, F.R., J.S. Baron, D.H. Campbell, K.D. Fausch, S.W. Hostetler, G.H. Leavesley, P.R. Leavitt, D.M. McKnight, and J.A. Stanford. 1997. "Assessment of Climate Change and Fresh water Ecosystems of the Rocky Mountains, USA and Canada." Hydrological Processes 11: 903-924.

[12] Houghton JT, MeiraFilho LG, Callander BA, Harris N, Kattenberg A, Maskell K 1996. Climate change 1995: the science of climate change. Contribution of WGI to the second assessment report of the Intergovernmental Panel on Climate Change. Cambridge University Press, Cambridge. 
[13] IPCC. 1996b. Climate Change 1995: Impacts, Adaptations and Mitigation of Climate Change: Scientific - Technical Analyses. Contribution of Working Group II to the Second Assessment Report of the Intergovernmental Panel on Climate Change. Cambridge University Press, NY.

[14] Kinfe Hailemariam. 1999. Impact of climate change on the water resources of Awash River Basin, Ethiopia. Clim Res 12: 91-96.

[15] Lijalem Zeray Abraham, Jackson Roehrig, and Dilnesaw Alamirew Chekol 2007. Climate Change Impact on Lake Ziway Watershed Water Availability, Ethiopia. Catchment and Lake Research.

[16] Mall .R. K. Akhilesh Gupta, Ranjeet Singh, R. S. Singh3 and L. S. Rathore 2006. Water resources and climate change: An Indian perspective: current science, vol. 90, NO. 12.

[17] Matalas, N.C., and M.B. Fiering. 1977. "Water Resource Systems Planning." In Climate, Climatic Change, and Water Supply. National Research Council.

[18] Meyer, J.L. 1997. "Stream Health: Incorporating the Human Dimension to Advance Stream Ecology." Journal of the North American Benthological Society 16: 439-447.

[19] Nellemann, C., MacDevette, M., Manders, T., Eickhout, B., Svihus, B., Prins, A. and Kaltenborn, B. (eds) .2009. The
Environmental Food Crisis. The environment's role in averting future food crises. A UNEP rapid response assessment. Arendal, UNDP.

[20] NEPAD. 2002. Comprehensive Africa Agriculture Development Programme.

[21] OECD .2003. Poverty and Climate Change. Reducing vulnerability of the poor through adaptation. Paris: OECD.

[22] Schindler, D.W. 1997. "Wide spread Effects of Climatic Warming on Freshwater Ecosystems in North America." Hydrological Processes 11: 1043-1067.

[23] Shah, M., Fischer, G. and van Velthuizen, H. 2008. Food Security and Sustainable Agriculture. The Challenges of Climate Change in Sub-Saharan Africa. Laxenburg: International Institute for Applied Systems Analysis.

[24] Tsarouchi GT, Buytaert W (2013) Monitoring land use changes in the Upper Ganga Basin, India by using Remote Sensing and GIS techniques on Landsat 5 TM data. Geophys Res Abstr 15: 229.

[25] UNDP. 2008. Fighting Climate Change - Human Solidarity in a Divided World. New York: UNDP.

[26] Wiggins, S. 2006. Agricultural growth and poverty reduction: A scoping study. Working Paper No. 2 on Globalization, Growth and Poverty. Ottawa: IDRC. 